\title{
The Recovery of Odontogenic Sinusitis after Endoscopic Sinus Surgery
}

\author{
Jun Lee and Myoung Su Choi \\ Department of Otolaryngology-Head and Neck Surgery, Eulji University Medical Center, School of Medicine, Eulji University, \\ Daejeon, Korea
}

치성부비동염의 내시경하 부비동 수술 후 회복

이 준 최명수

을지대학교 의과대학 을지대학교병원 이비인후과학교실

\author{
Received August 12, 2020 \\ Revised October 6, 2020 \\ Accepted October 14, 2020 \\ Address for correspondence \\ Myoung Su Choi, MD \\ Department of Otolaryngology- \\ Head and Neck Surgery, \\ Eulji University Medical Center, \\ 95 Dunsanseo-ro, Seo-gu, \\ Daejeon 35233, Korea \\ Tel +82-42-611-3133 \\ Fax $+82-42-611-3136$ \\ E-mail mschoi@eulji.ac.kr
}

Background and Objectives The present study was designed to investigate the normalization period of the maxillary sinus after endoscopic sinus surgery (ESS) for odontogenic sinusitis (ODS) and factors related to it. The thickness of the maxillary sinus mucosa may reflect the improvement of symptoms and may help determine when the dental implant procedure will be possible.

Subjects and Method A total of 52 patients (34 males and 18 females) who were diagnosed with ODS and treated by ESS between 2014 and 2019 were enrolled in this study. The recovery status was defined as 'improved' when the mucosal thickness of the maxillary sinus was less than $4 \mathrm{~mm}$ measured by X-ray radiograph; 'partially improved' when it was 5 to $10 \mathrm{~mm}$, and 'little' when it was more than $10 \mathrm{~mm}$. The recovery period of the maxillary sinus after ESS was measured with an endoscope and X-ray radiograph and its related factors were analyzed.

Results About $2.1 \pm 1.6$ months were required for maxillary sinus to return to normal as investigated with an endoscope and X-ray radiograph. Assessed one month after ESS when compared to the three months after ESS, the results showed $100 \%$ recovery in 'improved' cases, $85.7 \%$ in 'partially improved' cases, and $50 \%$ in 'little' cases. 'The mucosal thickness of the maxillary sinus one month after ESS' $(p<0.001)$, 'oroantral fistula (OAF)' $(p=0.010)$, and 'delayed extraction' ( $p=0.028)$ were significantly related to the recovery period of the maxillary sinus by multiple regression analysis.

Conclusion ODS responds well to the ESS, and the mean period for returning to normal maxillary sinus was $2.1 \pm 1.6$ months. The normalization period of the maxillary sinus was positively correlated with the mucosal thickness of the maxillary sinus one month after ESS, $\mathrm{OAF}$, and delayed tooth extraction.

Korean J Otorhinolaryngol-Head Neck Surg 2021;64(6):399-406

Key Words Endoscopy $\cdot$ Maxillary sinus $\cdot$ Odontogenic $\cdot$ Sinusitis.

\section{Introduction}

Odontogenic sinusitis (ODS) is an inflammatory condition of the paranasal sinuses secondary to dental pathology or den-

This is an Open Access article distributed under the terms of the Creative Commons Attribution Non-Commercial License (https://creativecommons.org/licenses/by-nc/4.0) which permits unrestricted non-commercial use, distribution, and reproduction in any medium, provided the original work is properly cited. tal procedures. Past studies reported that ODS occupied around $10 \%$ of sinusitis, but recently many articles suggest that its incidence is increasing up from $25 \%$ to $40 \%$ of all chronic sinusitis. ${ }^{1-3)}$ In the case of unilateral maxillary sinusitis, ODS has been reported to be up to $70 \%{ }^{3)}$ The known infection routes are as follows: 1) spreading of endodontic infection or periodontitis to the sinus floor, 2) opening of an oroantral fistula 
(OAF) after tooth extraction, 3) tears of sinus floor mucosa during sinus augmentation, and 4) penetration of dental or graft materials into sinus. ${ }^{4)}$ Recently, the incidence of iatrogenic causes of ODS is increasing proportionally with the expansion of implant procedures. ${ }^{4)}$ The clinical symptoms of ODS are nasal obstruction, posterior nasal drip, pressure, or pain on the face which can be seen common in non-ODS, which make it difficult to distinguish ODS from non-ODS. About 50\% of patients with ODS may report previous dental surgery or infection, but only one-third of them may complain of dental pain that may provide a diagnostic clue. ${ }^{5)}$ Therefore, a physician's high degree of suspicion is important in diagnosing ODS.

The condition of the maxillary sinus mucosa is not only an indicator assessing the effectiveness of the treatment but also the basic condition for implementing dental implants later. The therapeutic goal of ODS is to resolve sinusitis symptoms and to recover the inflammation of maxillary sinus for dental implants when needed. Many studies have reported the effectiveness of the surgical outcome of ODS through a questionnaire on symptoms or endoscopic findings. ${ }^{6,7)}$ To the best of our knowledge, there are few studies on the effect of endoscopic sinus surgery (ESS) using the serial radiologic evaluation of maxillary sinus. Radiologic assessment of the surgical outcome may be more objective and intuitive than a questionnaire. The measurement of the mucosal thickness of maxillary sinus may reflect the recovery of the maxillary sinus and may help determine when dental implants are possible.

The present study was designed to evaluate the period of the maxillary sinus to return to normal after ESS for ODS and factors related to the normalization period.

\section{Subjects and Methods}

We retrospectively reviewed medical records of 52 patients diagnosed with dental origin sinusitis. Patients who had undergone ESS were included in this study after the failure of medical treatment. Before planning the ESS, amoxicillin combined with $\beta$-lactamase inhibitor was used as primary antibiotics for at least four weeks, and levofloxacin was used if primary antibiotics was ineffective or had side effects. Patients who are non-ODS and those who had ODS that improved by medical treatment were excluded. Patients who were unable to go to follow-up after ESS and who had not taken X-ray radiographs and endoscopic exams regularly were excluded. This study was conducted with the approval of the Institutional Review Board (EMC-001-2020110).

\section{Procedures}

In all patients, a functional ESS was performed on the involved sinus under general or local anesthesia. During ESS operation, the natural ostium of the maxillary sinus was opened large as possible to remove and irrigate residues from the inside and to allow the physician to inspect the maxillary sinus with endoscope easily later. The polyps in the maxillary sinus were removed transnasally as possible, the canine fossa was punctured, and the polyps were shaved under an angled endoscope when the polyps were not completely removed by the transnasal approach. After surgery, amoxicillin with/without clavulanate was used for 1 to 2 weeks in addition to saline irrigation. We replaced it with amoxicillin with $\beta$-lactamase inhibitor or levofloxacin when there was no improvement or kept discharging from maxillary sinus. All patients underwent ENT examinations with simple X-ray radiographs and an endoscope at 14, 30, 45, 60, and 90 days after surgery (Fig. 1). In cases of persistent infection or delayed improvement, patients were examined weekly. The average follow-up duration was 12.2 months (range, 4-23 months).

\section{Measurement of mucosal thickness of the maxillary sinus by simple $X$-ray radiograph}

Patients were subjected to Waters' view at follow-up. Mucosal thickening was measured at the midpoint of each of the superior, medial, and inferolateral sides of the affected maxillary sinus on the Waters' view image. When the mucosal thickening was observed on all three sides, the mean of the thickness was measured by their three sides; when the mucosal thickening was observed on two sides, the mean was measured by their two sides; and when the mucosal thickening was observed only on the inferolateral side, the value of the thickness of the inferolateral side was determined according to the mucosal thickness of the maxillary sinus (Fig. 2). We defined ODS as 'improved' when the mucosal thickness is $4 \mathrm{~mm}$ or less, 'partially improved' when it is 5 to $10 \mathrm{~mm}$, and 'little' when it is more than $10 \mathrm{~mm}$ by Waters' view.

\section{Recovery status evaluation of the maxillary sinus}

The recovery status was defined as 'recovery' when maxillary sinus was assessed to be 'improved' by the X-ray radiograph and there was no purulent discharge or edema by endoscopic exam, and it was defined as 'not yet' when maxillary sinus was assessed to be any state by the X-ray radiograph and some purulent discharge or edema was found inside the maxillary sinus by the endoscopic exam. All patients 

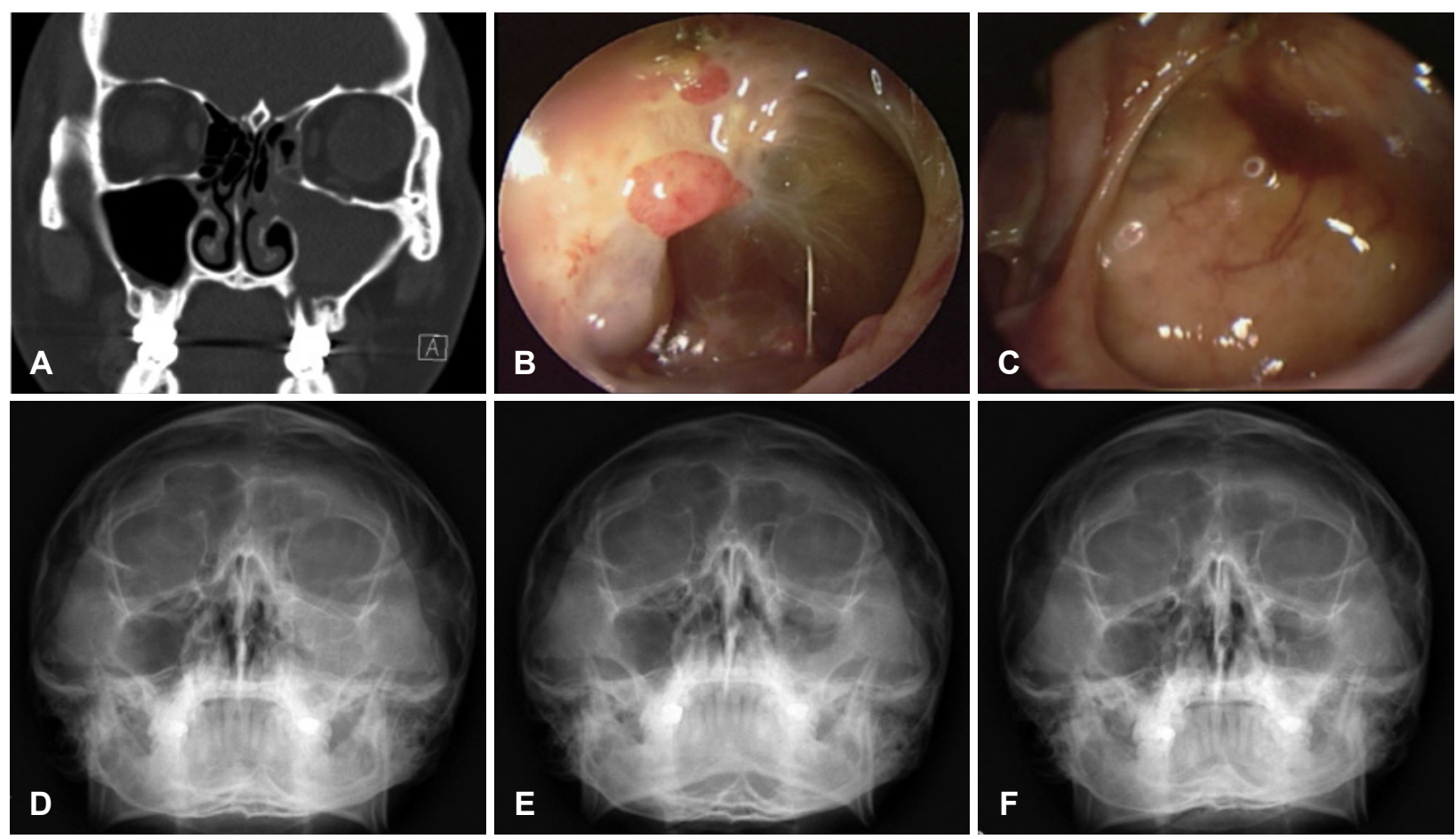

Fig. 1. Representative case of the healing course of maxillary sinus mucosa after ESS (A, D: before ESS; B, E: two weeks after ESS; C, F: two months after ESS). ESS: endoscopic sinus surgery.

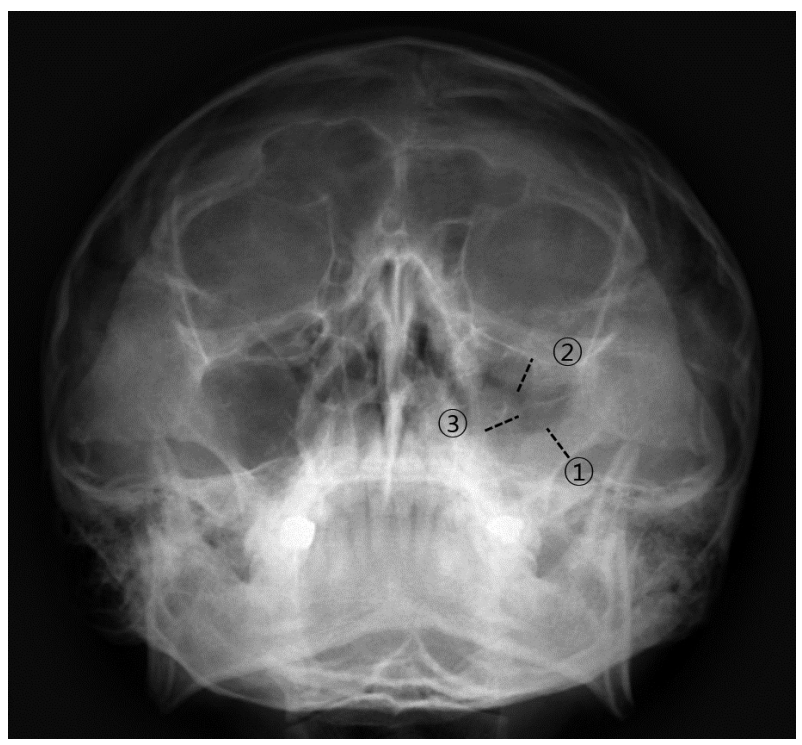

Fig. 2. The thickness of the maxillary sinus mucosa was measured as the mean distance from the midpoint of all three sides in Waters' view.

were determined to evaluate the recovery status of the maxillary sinus within three months.

\section{Statistics}

Statistical analysis was carried out using SPSS 18.0 (SPSS Inc., Chicago, IL, USA). It was assumed that $p<0.05$ is significant. The prevalence of the various clinical variables was investigated. The period returning to normal maxillary sinus was compared in each etiology of ODS using a one-way analysis of variance test, and the period returning to normal was also compared according to the timing of dental extraction using a t-test. Multiple linear regression analysis was used to analyze factors associated with recovery periods after ESS.

\section{Results}

A total of 85 patients were diagnosed with ODS. Of them, 52 patients were enrolled in this study, except for 26 who had improved with medical treatment, and 7 who had not followup regularly. A total of 56 sides of 52 patients were included in this study, and bilateral ODS was confirmed in four patients. The mean age was $60.3 \pm 3.8$ years, and the male-to-female ratio was 34/18. The leading cause of ODS was periapical pathology (periapical periodontitis, periapical abscess, and root remnants) with 30 cases (53.6\%), followed by implant-related cases with 17 cases (30.3\%). Among implant-related cases, penetration into the floor of the maxillary sinus by implant fixture was $14.3 \%$, periimplantitis was $5.4 \%$, graft failure during sinus floor augmentation was $8.9 \%$, and misplaced implant fixture as a foreign body was $1.8 \%$. The cases of ODS related to the tooth extraction were $9(16.1 \%)$ (Table 1).

There were 23 cases (41.1\%) involving maxillary and eth- 
Table 1. Clinical characteristics of patients $(n=52)$

\begin{tabular}{lc}
\hline \multicolumn{1}{c}{ Clinical characteristics of patients } & $\mathrm{n}(\%)$ \\
\hline Sinuses & 56 sides \\
Age (years) & $60.3 \pm 3.8$ \\
Male/female & $34 / 18$ \\
Symptoms duration (months) & $6.1 \pm 8.5$ \\
Etiology & \\
Periapical pathology & $30(53.6)$ \\
Tooth extraction & $9(16.1)$ \\
Implant-related cause & $17(30.3)$ \\
$\quad$ Penetration of implant fixture & $8(14.3)$ \\
$\quad$ Periimplantitis & $3(5.4)$ \\
$\quad$ Sinus augmentation failure & $5(8.9)$ \\
$\quad$ Misplaced foreign body & $1(1.8)$ \\
Lund-Kennedy endoscopic scores & $3.4 \pm 1.7$ \\
Septal deviation & $6(10.7)$ \\
Oroantral fistulae & $6(10.7)$ \\
Diabetes & $12(21.4)$ \\
Involves sinuses & \\
Only maxillary & 10 sides (17.9) \\
Maxillary, ethmoid & 23 sides (41.1) \\
Frontal, ethmoid, maxillary & 21 sides (37.5) \\
Ethmoid, maxillary, sphenoid & 1 side (1.8) \\
Pan-sinuses & 1 side (1.8) \\
Presenting symptoms & \\
Nasal obstruction & $48(85.7)$ \\
Purulent rhinorrhea & $47(83.9)$ \\
Postnasal drip & $32(57.1)$ \\
Foul odor & $21(37.5)$ \\
Cheek pain & $12(21.4)$ \\
\hline & $5(8.9)$ \\
Orbital pain & $1(1.8)$ \\
Facial numbness & $1.8)$ \\
\hline
\end{tabular}

moid sinuses together in preoperative $\mathrm{CT}$, followed by 21 cases (37.5\%) involving frontal, ethmoid, and maxillary sinuses, followed by 10 cases (17.9\%) involving only maxillary sinus. And, there was one case $(1.8 \%)$ of pan-sinus involvement.

The mean of the Lund-Kennedy endoscopic score was 3.4 \pm 1.7 points. And, there were six cases in which septoplasty was performed along with ESS due to severe deviation of the nasal septum. Moreover, there were six cases of OAF or communication. Four of them were closed spontaneously after ESS, and two were closed by a flap or suture technique by dentists.

The presenting symptoms of ODS were as shown in Table 1. Presenting symptoms improved mostly within 1 to 2 weeks after ESS. Cheek pain was observed in $21.4 \%$, and one patient complained of cheek numbness assumed to pressure on the infraorbital nerve, and its symptom gradually recovered 1 month after ESS surgery.
Improvement rate of maxillary sinus mucosa over time after ESS

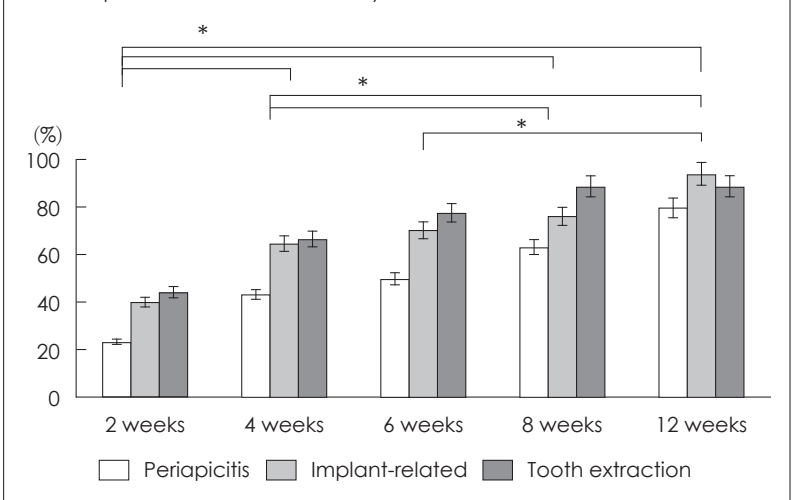

Fig. 3. Change of improvement of maxillary sinus mucosa over time after ESS. Bars show improvement rate of maxillary sinus mucosa. No significant differences were observed in improvement rate according to the etiology of odontogenic sinusitis. Differences in improvement rate among weeks were analyzed using chi-square test. $\left({ }^{*} p<0.05\right)$. ESS: endoscopic sinus surgery.

A total of 30 cases (53.6\%) have improved on X-ray 1 month following ESS. Among them, periapical pathology was 43.3\%, implant-related was $64.7 \%$, and tooth extraction was $66.7 \%$. The number of improvement on X-ray increased over time, indicating that by the 3 months, approximately 85 percent had improved, with no significant difference among etiologies (Fig. 3).

About $2.2 \pm 1.6$ months for maxillary sinus was required to return to normal evaluated by the endoscope and X-ray radiograph. There was no difference in recovery period according to the etiology of ODS ( $p=0.590)$. By the 12th week, 16 out of 17 cases were recovered in implant-related, eight out of nine cases were recovered in tooth extraction but it took about 2.5 months because of a delayed case needed to repair OAF, and 24 out of 30 cases were recovered in periapical pathology and remaining six wre normalized within three to four months, taking an average 2.3 months (Fig. 3, Table 2). The recovery period was significantly shorter in the cases of tooth extraction preoperatively or within one month of ESS than in the cases of conservative treatment in the periapical pathology $(p=0.046)$ (Table 2).

One of 56 ESS cases required revision surgery to open the obstructed ostium of the maxillary sinus, and the remaining 55 cases returned to normal, showing a high success rate (98.2\%).

Significant factors were found to be related to the recovery period for 'mucosal thickness of maxillary sinus one month after ESS' $(p<0.001)$, 'OAF' ( $p=0.010)$, and 'delayed dental extraction' ( $p=0.028$ ) by multiple regression analysis (Table 3 ). The symptom duration or etiology did not significantly affect the recovery period. 
Cases of delayed recovery of maxillary sinus mucosa for more than three months were caused by delayed causal tooth extraction, delayed OAF closure, prolonged antibiotic treatment due to osteomyelitis, and restenosis of antrostomy site (Table 4).

Table 2. The normalization period of the maxillary sinus after ESS according to the etiology and treatment methods of causative teeth

\begin{tabular}{lc}
\hline $\begin{array}{c}\text { Normalization period of the maxillary sinus } \\
\text { after ESS }\end{array}$ & $\begin{array}{c}\text { Duration } \\
(\text { months })\end{array}$ \\
\hline Mean normalization period $(n=56)$ & $2.2 \pm 1.6$ \\
Etiology & $\left(p=0.590^{*}\right)$ \\
Periapical pathology $(n=30)$ & $2.3 \pm 1.7$ \\
Tooth extraction $(n=9)$ & $2.5 \pm 1.8$ \\
Implant-related cause $(n=17)$ & $1.9 \pm 1.2$ \\
Tx. methods of causative teeth & $\left(p=0.046^{\dagger}\right)$ \\
Teeth ext. before or within 1 mo. of ESS $(n=18)$ & $1.7 \pm 1.1$ \\
Conservative (RCT or apicoectomy) $(n=12)$ & $3.1 \pm 2.1$ \\
\multicolumn{2}{c}{ Additional ext. without improvement (3 of 12) } \\
\hline
\end{tabular}

*one-way analysis of variance test, ${ }^{\dagger} t$-test. ESS: endoscopic sinus surgery, Tx.: treatment, mo.: month, ext.: extraction, RCT: root canal therapy

Table 3. Multiple linear regression analysis for factors affecting normalization period of the maxillary sinus after ESS

\begin{tabular}{lccccc}
\hline \multicolumn{1}{c}{ Variables } & $B$ & SE & $\beta$ & p value & VIF \\
\hline $\begin{array}{l}\text { MT of the MS 1 month } \\
\text { after ESS }\end{array}$ & 0.195 & 0.021 & 0.743 & $<0.001$ & 1.159 \\
Etiology & -0.109 & 0.119 & -0.074 & 0.363 & 1.167 \\
Age & 0.012 & 0.010 & 0.090 & 0.251 & 1.083 \\
LKE score & 0.049 & 0.073 & 0.053 & 0.502 & 1.104 \\
Duration & -0.001 & 0.015 & 0.004 & 0.958 & 1.264 \\
Involved sinuses & 0.279 & 0.144 & 0.152 & 0.058 & 1.095 \\
Oroantral fistula & 1.047 & 0.391 & 0.209 & 0.010 & 1.101 \\
$\begin{array}{l}\text { Delayed extraction } \\
\text { ESS: endoscopic sinus surgery, MT: mucosal thickness, MS: }\end{array}$ & -1.308 & 0.577 & -0.191 & 0.028 & 1.269 \\
$\begin{array}{l}\text { maxillary sinus, LKE: Lund-Kennedy endoscopic score, VIF: vari- } \\
\text { ance inflation factor }\end{array}$ & & & & &
\end{tabular}

\section{Discussion}

Although ESS position for ODS is the same as in the cases of non-ODS as it aims to improve sinusitis symptoms but may differ in that it should prepare maxillary sinus inflammationfree state to enable implant procedures when needed. Because complications related to implant procedure can be reduced only when the maxillary sinus is normalized, ODS is known to be well responded to ESS and its success rate is known to be high. ${ }^{6,7)}$ But, it has not been known well how long the maxillary sinus will take to normalize after ESS. In our study, the main symptoms of ODS improved within 1 month after ESS which is similar to other studies, and the period of the maxillary sinus returning to normal took about 2 months, which might suggest that implant procedures should be recommended for at least more than 2 months after ESS. This information may be useful to consult patients who are going to undergo ESS for ODS. Patients want to know when implant procedure is possible along with the resolution of sinusitis symptoms. The symptoms related to pus or fungal balls that have accumulated in the sinus improve immediately after surgical removal, but radiologic haziness related to the edema or polyps takes several weeks to months to return to a normal state. The factors related to the period of normalization were not significantly affected by the dental etiology in our study. However, the period was affected by the method of treating the causative teeth. Comparing dental treatments to determine whether to extract teeth or preserve them in treating periapical pathology in our study, the period of the maxillary sinus returning to normal was significantly shorter when teeth were extracted before or after ESS within a month than when treated with conservative methods as root canal therapy or an apicoectomy. And, there were 3 out of 12 cases (25\%) where teeth had to be extracted eventually because inflammation of the maxillary sinus was not controlled. In addition to delayed tooth

Table 4. Cases of delayed recovery of the maxillary sinus mucosa after ESS

\begin{tabular}{rllccccl}
\hline No. & \multicolumn{1}{c}{ Etiology } & Sex & Age & Dur. (months) & PHx. & Sinuses & \multicolumn{1}{c}{ Possible causes } \\
\hline 2 & $\# 25$ periapicitis & Female & 63 & 25 & RA & F, E, M & Delayed causal tooth extraction \\
14 & $\# 16, \# 17$ periapicitis & Male & 47 & 3 & & F, E, M & Restenosis of middle meatal antrostomy \\
21 & $\# 26$ periapical abscess & Female & 34 & 2 & & PAN & Delayed causal tooth extraction \\
30 & Peri-implantitis \#56 & Female & 73 & 2 & DM & E, M & Osteomyelitis \\
31 & Tooth extaction \#16 & Female & 71 & 2 & & E, M & Delayed closure of OAF \\
44 & $\# 26$ periapical abscess & Male & 55 & 48 & & E, M & Unknown \\
48 & $\# 27$ Periapicitis & Male & 60 & 3 & DM & F, E, M & Delayed closure of OAF
\end{tabular}

ESS: endoscopic sinus surgery, No.: number, Dur.: durations, PHx.: past medical history, RA: rheumatoid arthritis, DM: diabetes mellitus, F: frontal, E: ethmoid, M: maxillary, PAN: pan-sinuses, OAF: oroantral fistula 
extraction, OAF was also a factor that delayed the normalization of the maxillary sinus after ESS. Without OAF being closed completely, maxillary sinus cannot be expected to return into an inflammation-free state. An OAF can be operated simultaneously or later with ESS, but if the size of the OAF is small, we can wait to close itself after ESS.

$\mathrm{X}$-ray radiograph taken one month after ESS may be a useful tool estimating the prognosis of the maxillary sinus. When the X-ray radiograph was assessed to be 'improved' (mucosal thickness is less than $4 \mathrm{~mm}$ ) or 'partially improved' (mucosal thickness is 5 to $10 \mathrm{~mm}$ ), the recovery rate of maxillary sinus evaluated three months after ESS reached about 95\%. However, the recovery rate reduced to $50 \%$ when the mucosal thickness one month after ESS was assessed as 'little' (mucosal thickness is more than $10 \mathrm{~mm}$ ). The normalization period of the maxillary sinus took about two months in this study so that the X-ray radiograph one month after ESS, or half of two months, seems to be reasonable for checking the prognosis of the ESS. Therefore, if the mucosal thickness of maxillary sinus does not improve significantly in the X-ray radiograph after one month, it may mean that a physician should check for other factors such as the opening of the maxillary sinus, closure of OAF, and other causal teeth properly treated which affect the prognosis of ODS.

In our study, the causes of ODS were classified into three categories: periapical pathology (53.6\%), tooth extraction (16.1\%), and implant-related cause $(30.3 \%)$. The composition of the etiology of ODS had been often reported differently by other studies. In the past, the predominant cause of ODS was tooth extraction. ${ }^{8-10)}$ But, a recent review investigating the etiology of ODS among 674 patients reported that an iatrogenic cause accounted for $65.7 \%$ of cases, apical pathology accounted for $25.1 \%$ of cases, and periodontitis accounted for $8.3 \%{ }^{11)}$ This result may reflect the recent increase in implant procedures. The proximity between the teeth roots and the maxillary sinus floor is a contributing factor to pathophysiology in ODS. Pulpal infection can easily extend into periapical osteitis, followed by a periapical abscess that can be identified by CT. Therefore, when diagnosing ODS through CT, a close examination of the root of teeth and maxillary sinus floor should be taken. Selden, ${ }^{12,13)}$ who explained the mechanism of endodontic complication spreading by pulpal disease, reported radiological findings as follows: periapical radiolucency or lamina dura loss in radiographs, faintly radiopaque mass bulging into the sinus wall, and variable radiopacities on the inferior sinus wall. The sinus floor augmentation by lifting the
Schneiderian membrane and placing a bone graft is a preimplant procedure that is common for those who have lost teeth and aims to increase the thickness of bone in the posterior maxilla. The main problem is tearing of the Schneiderian membrane during sinus floor augmentation, and it has been known to occur in around $7 \%$ to $35 \%{ }^{14-16)}$ Small tear easily can be sealed with a collagen membrane or fibrine glue sealants and rarely cause sinusitis. However, a large tear may cause sinusitis with graft infection or graft displacement into the antrum and eventually fail to fill sufficient thickness, which may cause instability after implant procedure. ${ }^{17)}$

In this study, there were eight cases of penetration of implant fixtures over $4 \mathrm{~mm}$ by CT among implant-related cases. Of the eight cases, pus was found in six cases and fungal balls were found in two. There has been controversy over whether penetration of implant fixture causes ODS, except for the displacement of the implant. Chen, et al., ${ }^{18)}$ examining 18 cases of implant-related sinusitis, reported that 15 out of 18 patients underwent ESS; two of them had removed implants before the ESS, four had removed implants due to a recurrence after the ESS, and the other nine had improved without removal implants after the ESS. This study suggested that the possible causes for ODS after implant penetration into the sinus were foreign body reaction to the exposed implant, penetration as a route for infection from the oral cavity, or an OAF caused by the removal of the penetrated implant. On the contrary, Jung, et al., ${ }^{19)}$ prospectively examining 9 patients with 23 implants that had penetrated the maxillary sinus floor over $4 \mathrm{~mm}$ by CT, reported that only maxillary sinus membrane thickening happened in 14 of the 23 implants without resulting in any maxillary sinusitis.

The protocol of ODS has not been yet clear. In 2018, the American Academy of Endodontics suggested a position statement on maxillary sinusitis originated from endodontic causes, putting emphasis that dental treatment (e.g., root canal therapy, apicoectomy, or tooth extraction) should be preceded, followed by ESS only if needed. ${ }^{20)}$ Many studies showed that a majority of patients improved with dental treatment alone, and ESS alone for ODS often fails to cure and even recurs until dental treatment. ${ }^{21)}$ A recent retrospective study was conducted on 43 patients with ODS to identify predictors undergoing ESS. $48 \%$ of patients ultimately required ESS, and 52\% of patients improved with medical and dental treatment without ESS. Predictive factors for ESS in ODS were prior to dental procedures and ostiomeatal complex involvement. ${ }^{22)}$ However, if symptoms of sinusitis are severe or patients want a 
rapid improvement of symptoms, ESS may be implemented first. Craig, et al. ${ }^{6}$ prospectively studied 37 symptomatic ODS patients whose medical treatment failed, and patients were allowed to voluntarily choose the order for primary dental treatment or primary ESS. It took 7 to 12.5 days for the primary ESS group and 38 to 56.2 days for the primary dental group to resolve cardinal sinusitis symptoms. The group that selected the ESS as a primary treatment showed faster and more significant symptom resolution. Recently, it has been approached in this way that lower grades of sinusitis without displacement of graft, foreign bodies, fungal balls, or antral polyps are resolved with medical and dental treatment, but significant sinusitis involving ostiomeatal complex or showing total opacification of maxillary sinus requires ESS first. After ESS, it is reassessed whether to remove the dental implant, to close OAF, or to extract causative teeth. This algorithm may preserve dental implants as much as possible and may reduce the burden of dental treatment with the fast improvement of symptoms. ${ }^{18)}$

In this study, the process of normalization of the maxillary sinus was not comparable between ODS and non-ODS after ESS due to the retrospective research design and absence of the serial X-rays. It is expected that comparing the normalization process through forward research will provide a better understanding of the effect of odontogenic causes on maxillary sinus mucosa. Another limitation of this study is the selection bias. In our study, periapical pathology occurs in more than $50 \%$ and tooth extraction occurs in less than $20 \%$, in which the composition may reflect well the response of ESS. Since the composition ratio of the etiology of ODS may vary across studies, the surgical outcome of ESS may also differ according to the composition ratio. Therefore, our result may not reflect the natural course after ESS for ODS. Additionally, it may be inaccurate in this study to use simple X-ray radiographs rather than $\mathrm{CT}$ for measuring the mucosal thickness of the maxillary sinus. CT is known to be the gold standard in the diagnosis of maxillary sinus disease due to its high resolution. CT can reflect well the 3D stereoscopic characteristics of the maxillary sinus, but X-ray can only show overlapping 2D images. However, X-ray has the advantage of low radiation and low price, which make it easy to repeat. If the ostium of the maxillary sinus is opened wide during ESS, then, an X-ray radiograph combined with an angled endoscope may sufficiently reflect the state of maxillary sinus compared to CT.

In conclusion, ODS responds well to the ESS, and the mean period returning to normal maxillary sinus was $2.1 \pm 1.6$ months.
The normalization period of the maxillary sinus was positively correlated with the mucosal thickness of the maxillary sinus one month after ESS, OAF, and delayed tooth extraction.

\section{Acknowledgments}

None.

\section{Author Contribution}

Conceptualization: Myoung Su Choi. Data curation: Jun Lee. Formal analysis: Jun Lee. Investigation: Jun Lee. Methodology: Myoung Su Choi. Writing — original draft: Myoung Su Choi. Writing—review \& editing: Myoung Su Choi.

\section{ORCID}

Myoung Su Choi https://orcid.org/0000-0003-4553-7808

\section{REFERENCES}

1) Melén I, Lindahl L, Andréasson L, Rundcrantz H. Chronic maxillary sinusitis: Definition, diagnosis and relation to dental infections and nasal polyposis. Acta Otolaryngol 1986;101(3-4):320-7.

2) Puglisi S, Privitera S, Maiolino L, Serra A, Garotta M, Blandino G, et al. Bacteriological findings and antimicrobial resistance in odontogenic and non-odontogenic chronic maxillary sinusitis. J Med Microbiol 2011;60(Pt 9):1353-9.

3) Matsumoto Y, Ikeda T, Yokoi H, Kohno N. Association between odontogenic infections and unilateral sinus opacification. Auris Nasus Larynx 2015;42(4):288-93.

4) Felisati G, Chiapasco M, Lozza P, Saibene AM, Pipolo C, Zaniboni $\mathrm{M}$, et al. Sinonasal complications resulting from dental treatment: Outcome-oriented proposal of classification and surgical protocol. Am J Rhinol Allergy 2013;27(4):e101-6.

5) Little RE, Long CM, Loehrl TA, Poetker DM. Odontogenic sinusitis: A review of the current literature. Laryngoscope Investig Otolaryngol 2018;3(2):110-4.

6) Craig JR, McHugh CI, Griggs ZH, Peterson EI. Optimal timing of endoscopic sinus surgery for odontogenic sinusitis. Laryngoscope 2019;129(9):1976-83.

7) Hoskison E, Daniel M, Rowson JE, Jones NS. Evidence of an increase in the incidence of odontogenic sinusitis over the last decade in the UK. J Laryngol Otol 2012;126(1):43-6.

8) Anand VK. Epidemiology and economic impact of rhinosinusitis. Ann Otol Rhinol Laryngol Suppl 2004;193:3-5.

9) Mehra P, Jeong D. Maxillary sinusitis of odontogenic origin. Curr Allergy Asthma Rep 2009;9(3):238-43.

10) Arias-Irimia O, Barona-Dorado C, Santos-Marino JA, MartínezRodriguez N, Martínez-González JM. Meta-analysis of the etiology of odontogenic maxillary sinusitis. Med Oral Patol Oral Cir Bucal 2010;15(1):e70-3.

11) Lechien JR, Filleul O, Costa de Araujo P, Hsieh JW, Chantrain G, Saussez S. Chronic maxillary rhinosinusitis of dental origin: A systematic review of 674 patient cases. Int J Otolaryngol 2014; 2014:465173.

12) Selden HS. The interrelationship between the maxillary sinus and endodontics. Oral Surg Oral Med Oral Pathol 1974;38(4):623-9.

13) Selden HS. The endo-antral syndrome: An endodontic complication. J Am Dent Assoc 1989;119(3):397-8, 401-2.

14) Saibene AM, Pipolo GC, Lozza P, Maccari A, Portaleone SM, Scotti A, et al. Redefining boundaries in odontogenic sinusitis: A retrospective evaluation of extramaxillary involvement in 315 patients. Int Forum Allergy Rhinol 2014;4(12):1020-3.

15) Nimigean VR, Nimigean V, Maru N, Andressakis D, Balatsouras 
DG, Danielidis V. The maxillary sinus and its endodontic implications: Clinical study and review. B-ENT 2006;2(4):167-75.

16) Simuntis R, Kubilius R, Vaitkus S. Odontogenic maxillary sinusitis: A review. Stomatologija 2014;16(2):39-43.

17) Brook I. Sinusitis of odontogenic origin. Otolaryngol Head Neck Surg 2006;135(3):349-55.

18) Chen YW, Huang CC, Chang PH, Chen CW, Wu CC, Fu CH, et al. The characteristics and new treatment paradigm of dental implantrelated chronic rhinosinusitis. Am J Rhinol Allergy 2013;27(3): 237-44.

19) Jung JH, Choi BH, Jeong SM, Li J, Lee SH, Lee HJ. A retrospective study of the effects on sinus complications of exposing dental implants to the maxillary sinus cavity. Oral Surg Oral Med Oral Pathol Oral Radiol Endod 2007;103(5):623-5.

20) Tataryn RW, Lewis MJ, Horalek AL, Thompson CG, Cha BY, Pokorny AT. Maxillary sinusitis of endodontic origin: AAE position statement. 2018 Jan-Nov [cited 2020 Apr 10]. Available from: URL: https://www.aae.org/specialty/wp-content/uploads/sites/2/2018/04/ AAE_PositionStatement_MaxillarySinusitis.pdf.

21) Longhini AB, Ferguson BJ. Clinical aspects of odontogenic maxillary sinusitis: A case series. Int Forum Allergy Rhinol 2011;1(5):409-15.

22) Mattos JL, Ferguson BJ, Lee S. Predictive factors in patients undergoing endoscopic sinus surgery for odontogenic sinusitis. Int Forum Allergy Rhinol 2016;6(7):697-700. 